\title{
Spinal Epidural Lipomatosis: A Complication of Glucocorticoid Therapy
}

\author{
N. A. Russell, G. Belanger, B. G. Benoit, D. N. Latter, D. L. Finestone and G. W. Armstrong
}

\begin{abstract}
A 21-year-old woman receiving prolonged high dosage glucocorticoids developed spinal cord compression due to excessive accumulation of epidural fat. Computerized tomographic scanning confirmed the diagnosis and revealed a peculiar pattern of spinal cord displacement which we believe to be unique to compression by fat. Laminectomy did not afford relief, possibly because of prolonged neural compression or because of compression at a higher spinal level. Although an unusual complication of Cushing's syndrome, epidural lipomatosis should be considered when such a patient develops symptoms of spinal cord or cauda equina compression.
\end{abstract}

RÉSUMÉ: Une lipomatose épidurale a entraîné une compression médullaire chez une patiente de 21 ans, traitée longtemps avec de fortes doses de glucocorticoïdes. La tomographie axiale a permis d'établir le diagnostic en révélant un déplacement d'aspect singulier de la moëlle caractéristique des compressions par tissu adipeux. La laminectomie n’a pas produit les résultats escomptés, soit que la compression datait de trop longtemps, soit qu'étendue elle intéressait également des segments médullaires plus rostraux. Complication inusitée du syndrome de Cushing, la lipomatose épidurale se doit d'être retenue face à un tableau de compression de la moëlle épinière ou de la queue de cheval.

Can. J. Neurol. Sci. 1984; $11: 383-386$

The characteristic body habitus of Cushing's syndrome is due to excessive deposition of fat about the head, neck and trunk. This results from prolonged exposure of the peripheral tissues to increased amounts of glucocorticoid (Gold, 1979). Fat deposition due to exogenous steroid, has also been found in the mediastinum (Bodman and Condemi, 1967; Koerner and Sun, 1966; Price and Rigler, 1970; Santini and Williams, 1971; Teates, 1970), episternum (Lucerna et al., 1966), and presacral region (Sowerbutts, 1959). Lee et al. (1975) were the first to call attention to spinal epidural lipomatosis occurring under similar circumstances. They described a patient who had received prolonged high dosage corticosteroid therapy. Excess deposition of fat occurred in the spinal epidural space, resulting in cord compression, requiring laminectomy. Nine other cases have since been described (Archer and Smith, 1982; Chapman et al., 1981; George et al, 1983; Godeau et al., 1979; Guegan et al., 1982; Lipson et al., 1980). This report adds another case and discusses the efficacy of computerized tomographic (CT) scanning in the diagnosis.

\section{Case Report}

A 21-year-old woman was admitted to the Ottawa Civic Hospital in September of 1981 with a 5 month history of low back and leg pain. At the age of 7 , she had developed asthma, which required continuous treatment with prednisone. By age 15 the dosage had been established at $60 \mathrm{mg}$. daily: at age 18 it was increased to $80 \mathrm{mg}$. per day. Over the two years immediately preceding admission, the dosage had gradually been reduced to $24 \mathrm{mg}$. per day.

The back pain had occurred spontaneously and gradually increased in severity. It radiated down the back of her right leg to the dorsum of her foot. Later it spread to her left leg in a similar distribution. It was aggravated by movement and straining. Bowel and bladder function was normal.

At examination she exhibited the classical stigmata of advanced Cushing's syndrome. Her lumbar spine was tender. Straight leg raising produced pain at 70 degrees on each side. There was slight to moderate wasting and grade 4 weakness of both quadriceps muscles, and grade 4 weakness of the right tibialis anterior muscle and each extensor hallucis longus. Muscle tone was normal. Knee and ankle jerks were 3 plus. Sensation was unimpaired. Plantar responses were flexor and anal sphincter tone normal.

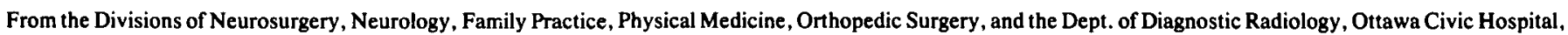
Children's Hospital of Eastern Ontario, Royal Ottawa Regional Rehabilitation Centre and the University of Ottawa.

Received January 9, 1984. Accepted in revised form May 1, 1984.

Reprint requests to: Neville A. Russell, M.D., 1081 Carling Avenue, Suite 308, Ottawa, Ontario K1Y 4G2 
Electromyographic studies of the legs revealed bilateral denervation and reinervation patterns encompassing the myotomes from L4 to SI. This electrical abnormality indicated a lower motor neuron lesion localized to the cauda equina. Its bilateral presence made neuropathy or lumbosacral plexopathy unlikely. The duration of the action potentials were increased, tending to exclude primary myopathy. The H-reflexes were unusually easy to obtain, indicating a separate abnormality i.e. an upper motor neuron lesion above the $\mathrm{S} 1$ segment.

Radiographs showed diffuse spinal osteoporosis with associated vertebral compression fractures from T3 to T9 and at all levels of the lumbar spine. The intervertebral disc spaces were preserved. The mediastinum was normal. No evidence of aseptic necrosis was seen in the hip or knee joints. CT scan of the lumbar spine showed no bony spinal stenosis nor any displacement of the vertebral compression fractures. An epidural mass, having the characteristic density of fat, was found to be encompassing the thecal sac at the $L 4 / 5$ level. The sac had adopted a triangular shape, the sides of the triangle being convex inwards (Figure 1). An identical abnormality was seen from T4 to T8 with the maximal compression being at $\mathrm{T} 6$. The bulk of the fat mass was distributed posterolaterally, the distribution corresponding to the convex sides of the triangle. CT body scan showed no evidence of mediastinal nor abdominal fat. A myelogram, using water soluable dye, showed a concentric extradural compression at the $\mathrm{L} 4-\mathrm{L} 5$ and the T4 - T8 levels. At the $L 4 / 5$ level this compression had caused a high grade but incomplete blockage to the passage of contrast material (Figure 2). There was similar, but less marked, blockage in the thoracic region. Both levels of extradural compression demonstrated by myelography, corresponded exactly to the levels of excessive fat distribution detected by the CT scan.
A bilateral laminectomy was performed from L3 to L5, since this was judged to be the area of maximal involvement. Abundant epidural fat was found throughout the exposed area. No disc abnormality was noted. In the immediate postoperative period and at follow-up ten months later there was no improvement in any of her symptoms or signs. Repeat electromyographic studies 8 months after surgery were identical to those done previously. Postoperative CT scan of the lumbar spine showed that the dural sac at the site of laminectomy had changed to the more normal circular shape from the previously noted triangular configuration (Figure 3 ). It was decided not to explore the thoracic spine, because of the patient's poor general health.

\section{Discussion}

The details of 9 previously reported cases of steroid induced epidural lipomatosis were recently analyzed (George et al., 1983). Severe back and leg pain were the presenting symptoms in all. Subsequently, spinal cord or cauda equina compression developed. The duration of the steroid therapy before the appearance of neurological deficit averaged 19 months. The dosage usually exceeded $40 \mathrm{mg}$. per day, although one patient (Chapman et al., 1981) had received $15 \mathrm{mg}$. of Prednisone daily for 48 months; another (Archer and Smith, 1982), not included in the analysis, had taken $15 \mathrm{mg}$. of Prednisone daily for 13 years. As previously noted with mediastinal fat (Koerner and

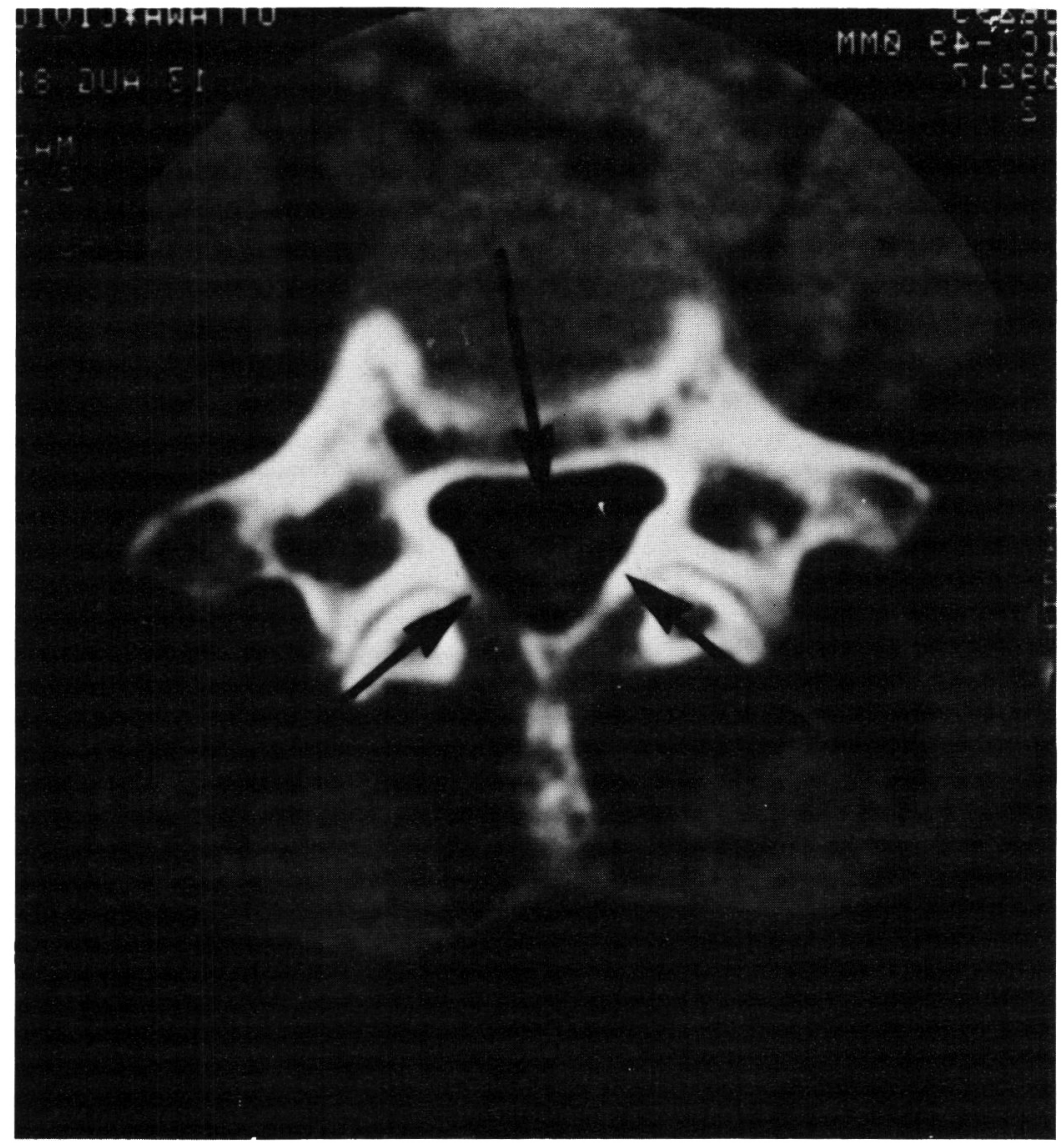

Figure 1 - Excessive epidural fat responsible for the triangular shaped dural tube, the sides of which are convex inward. 
Sun, 1966) these cases indicate that spinal epidural lipomatosis may be induced by low dose steroid if used for lengthy periods.

Several authors (Butcher and Sahan, 1979; George et al., 1983; Lipson et al., 1980; Matsui, 1981) have discussed the use of CT scanning in epidural lipomatosis. Adipose tissue is unique in that its $\mathrm{x}$-ray adsorption or specific density $(-80$ to -120 Hounsfield units) is lower than that of water. In our patient all measurements of epidural intraspinal mass were in the range for the specific density of fat. The dural sac had been compressed into an unusual triangular shape. We are not aware that this finding has been previously described. We attribute this to the soft or semisolid consistency of fat and to the fact that its main mass was situated posterolaterally. After decompression the sac returned to its usual more circular configuration. Myelography showed that the areas of epidural compression correlated with the levels of excess epidural fat demonstrated by the CT scan.

Mediastinal lipomatosis has been observed to regress after reduction of the steroid dose (Santini and Williams, 1971).

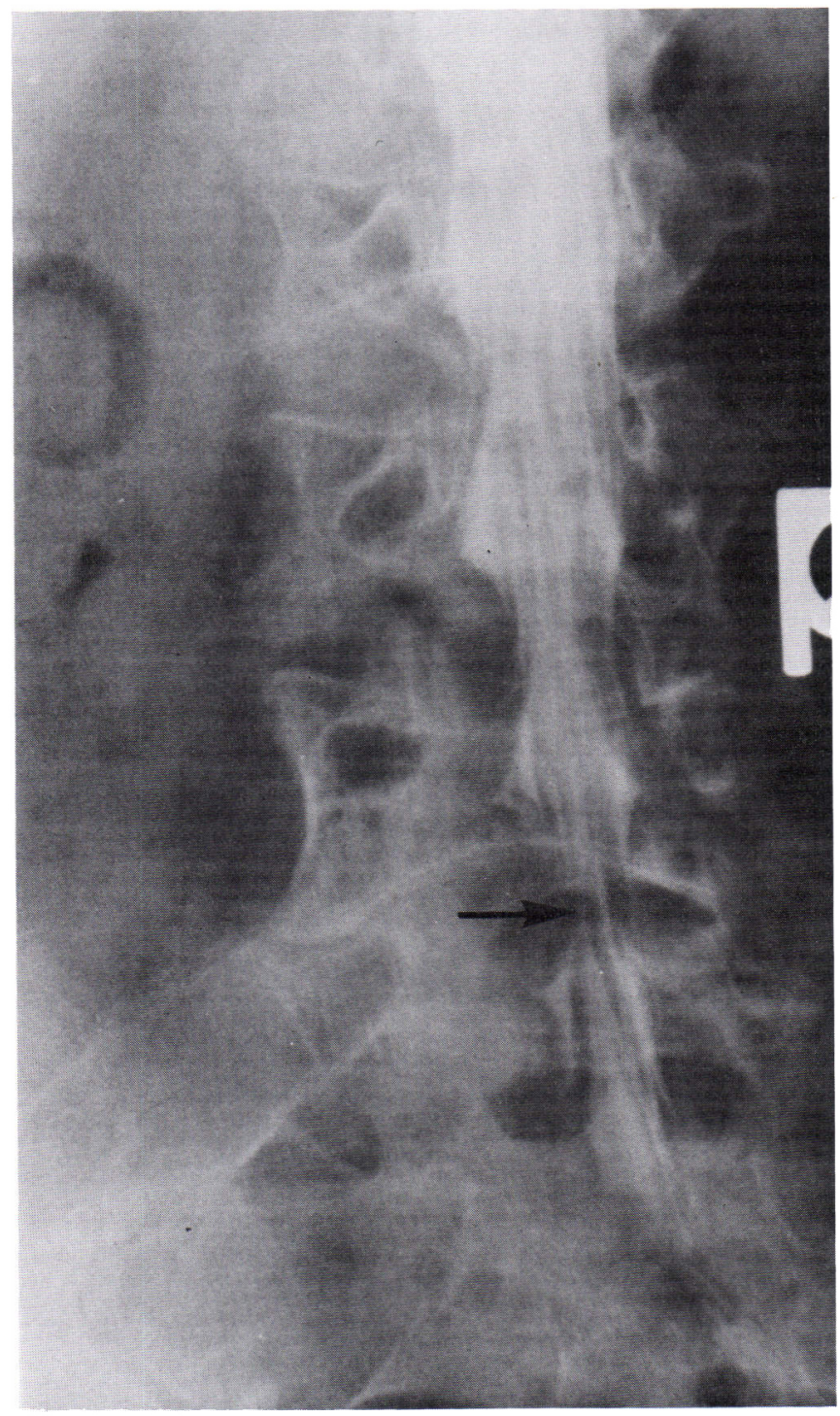

Figure 2 - Myelogram in anteroposterior view showing concentric extradural compression at the $L 4 \cdot$ - LS level.
Butcher and Sahan (1979) noted sparse epidural fat at the post mortem examination 7 weeks after the prednisone dose had been reduced to $20 \mathrm{mg}$. from $80 \mathrm{mg}$. per day. George et al. (1983) described a patient receiving high dose steroid because of renal disease, who had developed severe diabetes mellitus. Surgery was judged contraindicated because of his illness, and treatment was based upon steroid reduction and dietary control. Pain and neurologic deficit improved and the CT scan showed decrease in the amount of epidural fat.

All other patients reported were treated by decompressive laminectomy. There was no improvement in our patient nor in one of the others (Butcher and Sahan, 1979). Failure to improve when an adequate decompression was achieved indicates that epidural lipomatosis can cause irreversible neurologic damage if the compression is severe or longstanding (Chapman et al., 1981). In our patient both the CT scan and the electromyographic studies indicated that more than one level of spinal compression was present. Since only the lower level was decompressed, this may account for her failure to recover.

The appearance of a neurologic abnormality in a patient with Cushing's syndrome suggests a number of diagnostic possibilities (Chapman et al., 1981). The presence of spinal epidural lipomatosis can be established by CT scan. This will demonstrate epidural compression by a mass which as the specific density of fat. In 8 of the 10 reported cases, laminectomy resulted in prompt relief of symptoms. It is the treatment of choice if there is evidence of severe or progressing spinal cord or cauda equina compression. Steroid reduction and dietary manipulation may be reserved for those patients whose general condition is so precarious as to preclude surgery.

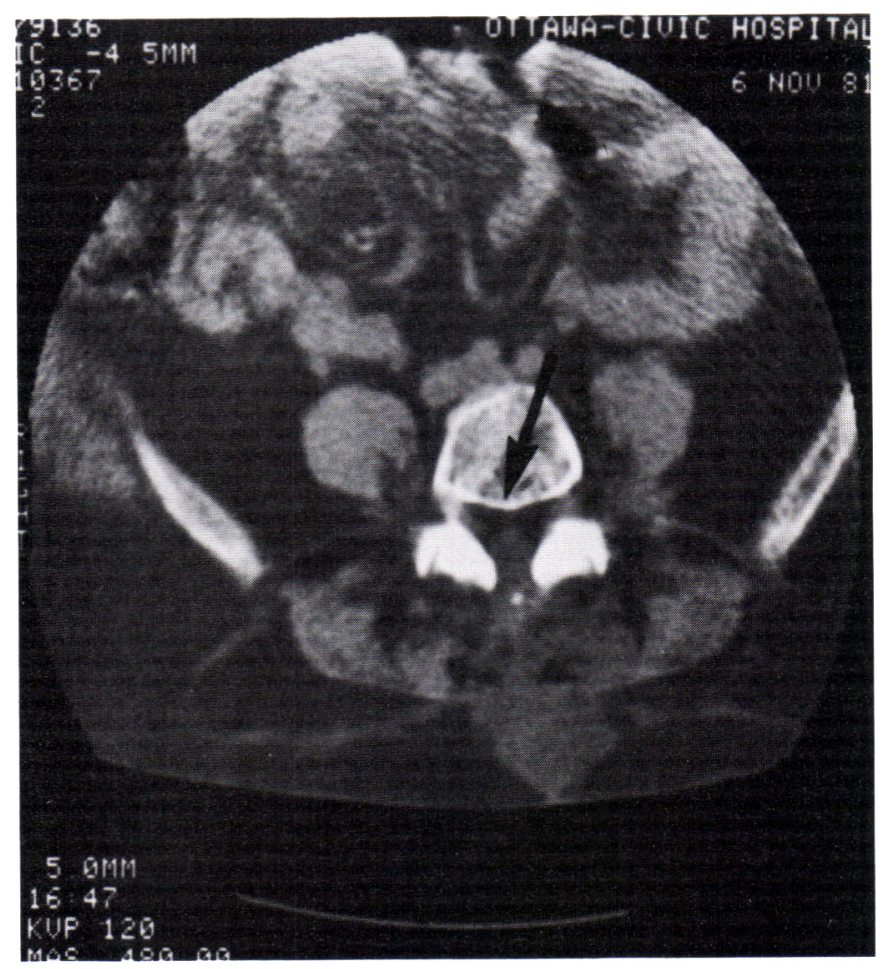

Figure 3 - Postoperatively the decompressed dural tube has returned to a circular shape. 


\section{REFERENCES}

Archer CR, Smith KR Jr (1982) Extradural lipomatosis simulating an acute herniated nucleus pulposus. J. Neurosurg. 57: 559-562.

Bodman SF, Condemi JJ (1967) Mediastinal widening in aitrogenic Cushing's syndrome. Ann. Intern. Med. 67: 399-402.

Butcher DL, Sahan SA (1979) Epidural lipomatosis: A complication of corticosteroid therapy. Ann. Intern. Med. 90: 60.

Chapman PH et al. (1981) Symptomatic spinal epidural lipomatosis associated with Cushing's syndrome. Neurosurgery 8: 724-727.

George WE Jr et al. (1979) Medical management of steroid induced epidural lipomatosis. N. Engl. J. Med. 308: 318-319.

Godeau P et al. (1979) Lipomatosis extradurale compressive accident inhabituel de la corticotherapie: (une observation). Neuv. Presse Méd. 90: 3889-3891.

Gold EM (1979) The Cushing's syndromes: Changing views of diagnosis and treatment. Ann. Intern. Med. 90: 829-844.

Guegan Y et al. (1982) Spinal cord by compression extradural fat after prolonged corticosteroid therapy: Case Report. J. Neurosurg. 36: 267-269.
Koerner HJ, Sun Di-C (1966) Mediastinal lipomatosis secondary to steroid therapy. Am. L. Roentgenol Radiat. Ther. Nuc. Med. 1988: 461-464.

Lee $\mathrm{M}$ et al. (1975) Spinal cord compression by extradural fat after renal transplantation. Med. J. Aust. 1: 201-203.

Lipson SJ et al. (1980) Spinal stenosis caused by epidural lipomatosis in Cushing's syndrome. N. Engl. J. Med. 302: 36.

Lucerna GE et al. (1966) "Dewlap": a corticosteroid induced episternal fatty tumor. N. Engl. J. Med. 275: 834-835.

Matsui T, In discussion of Chapman et al. (See ref. 4).

Price GE Jr, Rigler LG (1970) Widening of the mediastinum resulting from fat accumulation. Radiology. 96: 497-500.

Santini LC, Williams JL (1971) Mediastinal widening (Presumably lipomatosis) in Cushing's syndrome. N. Engl. J. Med. 284: 1357-1359. Sowerbutts JG (1959) Some uses of presacral oxygen insufflation. J. Radiol. (Lond.) 10: 201.

Teates CD (1970) Steroid induced mediastinal lipomatosis. Radiology. 96: $501-502$. 